\title{
ANALYSIS OF MINING-INDUCED SUBSIDENCE PREDICTION BY EXPONENT KNOTHE MODEL COMBINED WITH INSAR AND LEVELING
}

\author{
Lei Chen ${ }^{1,}$, Liguo Zhang ${ }^{2}$, Yixian Tang ${ }^{3}$, Hong Zhang ${ }^{3}$ \\ ${ }^{1}$ College of Geoscience and Surveying Engineering, China University of Mining and Technology (Beijing), Beijing, 100083 - \\ cl_cumtb@hotmail.com \\ ${ }^{2}$ Shandong provincial institute of land surveying and mapping, Jinan, 250102 - zlgrh@126.com \\ ${ }^{3}$ Key Laboratory of Digital Earth Science, Institute of Remote Sensing and Digital Earth, CAS, Beijing, 100094 - \\ yxtang@ceode.ac.cn, zhanghong@radi.ac.cn
}

Commission TC III, WG III/3

KEY WORDS: InSAR, Levelling, Exponent Knothe Model, Mining-induced Subsidence, Fitting, Prediction

\begin{abstract}
:
The principle of exponent Knothe model was introduced in detail and the variation process of mining subsidence with time was analysed based on the formulas of subsidence, subsidence velocity and subsidence acceleration in the paper. Five scenes of radar images and six levelling measurements were collected to extract ground deformation characteristics in one coal mining area in this study. Then the unknown parameters of exponent Knothe model were estimated by combined levelling data with deformation information along the line of sight obtained by InSAR technique. By compared the fitting and prediction results obtained by InSAR and levelling with that obtained only by levelling, it was shown that the accuracy of fitting and prediction combined with InSAR and levelling was obviously better than the other that. Therefore, the InSAR measurements can significantly improve the fitting and prediction accuracy of exponent Knothe model.
\end{abstract}

\section{INTRODUCTION}

Underground mining can induce the ground deformation and destroy the buildings, roads, farmlands and other infrastructures (Zhang et al, 2015). Therefore, it is necessary to subsidence prediction in the mining area for preventing the loss of life and property, and analysing the subsidence damages.

Mining-induced subsidence is a very complicated process and the subsidence process is mainly divided into three phases: initial subsidence, main subsidence and residual subsidence (Gao et al, 2009; Liu et al, 2010). Now a lot of empirical models and influence function models are used to predict the mining-induced subsidence, for example, Probability Integral Method (Wang et al, 2012; Guo et al, 2014), Logistic model (Zhang et al, 2009; Xi et al, 2013), Knothe model (Gao et al, 2009; Hu et al, 2011; Lian et al, 2011), and so on. Among these methods, Knothe model is one of the most widely used models in predicting ground subsidence in every surface point of workface in the coal mining area (Cui et al, 2001; Hu et al, 2011; Zhang and Liu, 2012). However, the deformation curve of subsidence velocity and acceleration is inconsistent with actual mining process (Han et al, 2012; Zhang et al, 2016). To overcome the shortage of Knothe model, segment Knothe model and exponent Knothe model are presented by some researchers (Shen et al, 2016; Chen et al, 2017). Assuming the middle moment is the moment of maximum subsidence velocity in segment Knothe model, but the expression is unreasonable to describe the process of actual mining subsidence (Zhang and Cui, 2017). Exponent Knothe model not only fits well with the curve of mining subsidence, but also with the formulas of subsidence velocity and acceleration (Liu et al, 2010).
Many researches have applied some traditional deformation monitoring techniques, combined with some subsidence models to estimate and predict subsidence information in the mining areas (Cui et al, 2001; Wang et al, 2012; Xi et al, 2013; Guo et al, 2014). Traditional mining-induced subsidence monitoring methods are usually divided into two kinds: levelling and Global Position System (GPS). The deformation characteristics of sparse points are achieved in levelling or GPS monitoring and a large number of sparse point sets need to be installed to retrieve the continuous surface deformation of wide study areas (Colesanti et al, 2005). Therefore, they need more timing consuming, more labor, higher cost and hardly get the surface deformation information of wide areas (Du et al, 2007; Cuenca et al, 2013).Interferometric synthetic aperture radar (InSAR) is a powerful technology that widely used in obtaining high precise digital elevation model and surface deformation characteristics of wide areas along the line of sight (LOS) (Zebker and Goldstein, 1986). And underground mining often introduces the large gradient deformation for a short time, such as one day or two days. However, the revisit cycle of SAR radar is fixed and we hardly get enough images according to the experiment requirements.

Based on above-mentioned literatures, mining-induced subsidence prediction was analysed by exponent Knothe model, combined with the advantage of InSAR and levelling in this paper. We collected six levelling measurements and five radar images to estimate the unknown parameters of exponent Knothe model. The accuracy of fitting and prediction of exponent Knothe model was further verified by comparing the fitting and prediction results with the measured data. Finally, by compared

\footnotetext{
* Lei Chen, cl_cumtb@hotmail.com
} 
the fitting and prediction results obtained by InSAR and levelling with that obtained only by levelling, the effect of InSAR technique on the fitting and prediction accuracy of exponent Knothe model was analysed in detail.

\section{EXPONENT KNOTHE MODEL}

\subsection{Principle of Knothe Model}

Knothe model is one of the most widely used to predict mininginduced subsidence and suppose that the speed of subsidence $\frac{d w(t)}{d t}$ at the moment $t$ is proportional to the difference between the final maximum subsidence $w_{m}$ and the subsidence value $w(t)$ at the moment $t$ (Cui et al, 2001; Hu et al, 2011):

$$
\frac{d w(t)}{d t}=c\left(w_{m}-w(t)\right)
$$

where $c$ is time influence coefficient related to the mechanical properties and mining condition.
According to the boundary condition at initial moment, the equation (1) can be transformed to the expression of subsidence value in the Knothe model:

$$
w(t)=w_{m}\left(1-e^{-c t}\right)
$$

To research the surface subsidence process expressed by Knothe model, the subsidence velocity $v(t)$ and acceleration $a(t)$ over time can be described respectively as follows:

$$
\begin{gathered}
v(t)=c w_{m} e^{-c t} \\
a(t)=-c^{2} w_{m} e^{-c t}
\end{gathered}
$$

Suppose that $w_{m}=-1, t=0 \cdots 500$ and $c=0.025$, the relationship curve between surface subsidence value $w(t)$, subsidence velocity $v(t)$ and subsidence acceleration $a(t)$ with time $t$ are constructed and shown in Figure 1 .
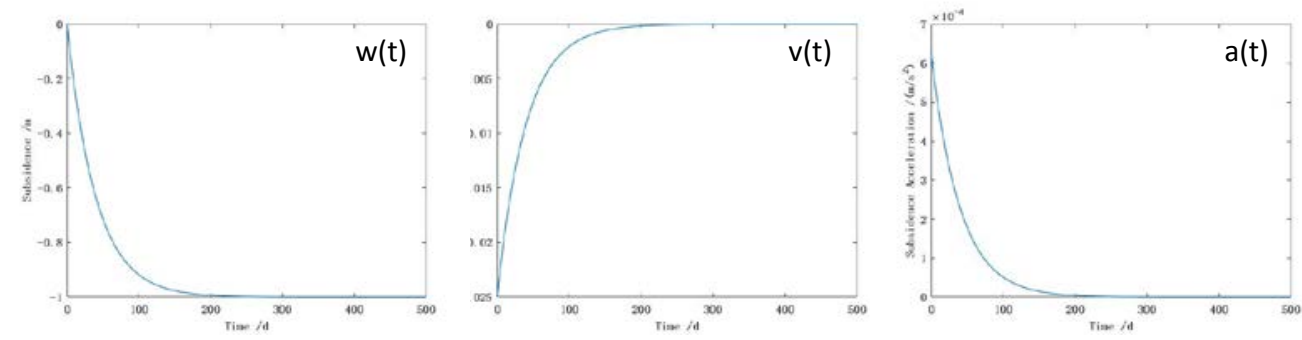

Figure 1. The surface subsidence, subsidence velocity and subsidence acceleration curve of Knothe model

As shown in Figure 1, the subsidence velocity and acceleration at the initial moment are not zero, so the subsidence curve expressed by Knothe model is not agreement with the actual process of coal mining subsidence.

\subsection{Principle of Exponent Knothe Model}

Exponent Knothe model is by adding a parameter to Knothe model and expressed as follows (Liu et al, 2010):

$$
w(t)=w_{m}\left(1-e^{-c t}\right)^{k}
$$

where $k$ is the fitting parameter.
To research the surface subsidence process expressed by exponent Knothe model, the curve formulas of subsidence velocity $v(t)$ and acceleration $a(t)$ are described respectively as follows:

$$
\begin{gathered}
v(t)=w_{m} k c e^{-c t}\left(1-e^{-c t}\right)^{k-1} \\
a(t)=w_{m}\left[-k c^{2} e^{-c t}\left(1-e^{-c t}\right)^{k-1}+k(k-1) c^{2} e^{-2 c t}\left(1-e^{-c t}\right)^{k-2}\right]
\end{gathered}
$$

Suppose that $w_{m}=-1, t=0 \cdots 500, c=0.025$ and $k=20$, the relationship curve between surface subsidence value $w(t)$, subsidence velocity $v(t)$ and subsidence acceleration $a(t)$ with time $t$ are shown in Figure 2.
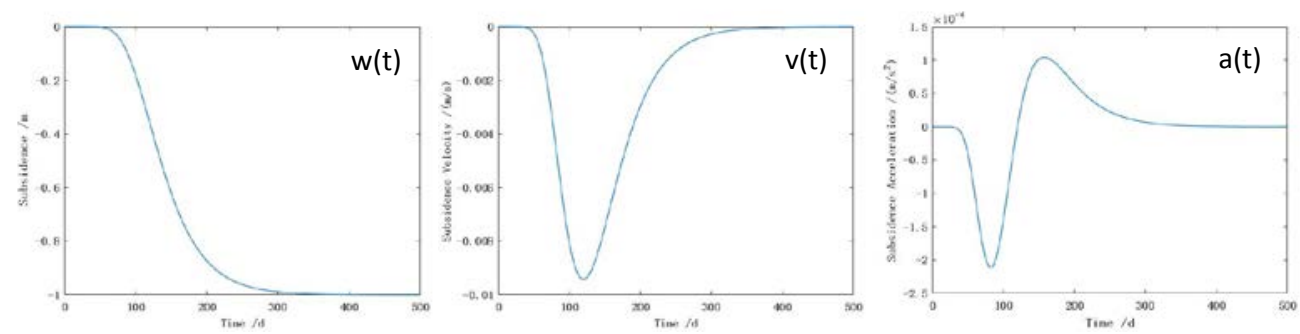

Figure 2. The surface subsidence, subsidence velocity and subsidence acceleration curve of exponent Knothe model 
It is shown that the deformation curve of exponent Knothe model can be well fitted with the actual mining process and the model are widely used to predict mining induced subsidence. Furthermore, only three unknown parameters are needed to be estimated to analysis mining-induced subsidence characteristics in reality (Liu et al, 2010).

\section{METHODOLOGY}

The block diagram of the used method in the paper was shown in Figure 3. The deformation information along LOS was obtained by D-InSAR technique and transformed to subsidence values. The time series subsidence information of every levelling point was extracted combined with D-InSAR results and levelling measurements. The unknown parameters of exponent Knothe model were estimated by time series subsidence of every levelling point and the effect of InSAR results on the fitting and prediction accuracy was analysed by comparing the estimated values using InSAR and levelling with that only using levelling measurements.

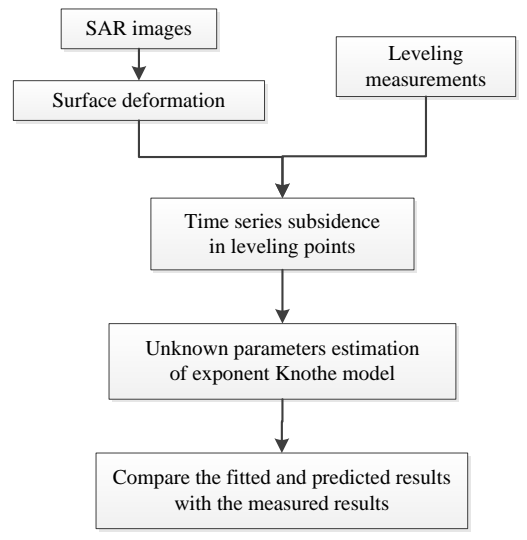

Figure 3. The block diagram of the used method

One image was selected as the reference image based on the principle of minimum sum of temporal, spatial and doppler baseline (Berardino et al., 2002) and other images were coregistered to the master image. Four interferograms were generated by two adjacent co-registered images and the external DEM was selected to remove the effect of topography phase in the interferograms. Now the traditional D-InSAR technique had been widely used to achieve the ground deformation induced by coal mining (Dong et al, 2013; Yerro et al, 2014), so we applied the D-InSAR technique to obtain the ground deformation along the line of sight of study area in the paper.

Subsidence was the main deformation component induced by underground mining and we neglected the horizontal deformation component in this paper (Yang et al, 2015, 2016). The deformation along line of sight (LOS) $d_{\text {LOS }}$ obtained by InSAR technique was transformed to the subsidence value $w$ as follows:

$$
w=\frac{d_{L O S}}{\cos \theta}
$$

where $\theta$ is the incidence angle of radar images.

Because of the difference between the date of levelling and SAR measurements, the least square fitting algorithm was applied to achieve the subsidence value in the levelling points on the time of SAR images acquisition. Suppose that we collected $\mathrm{M}$ InSAR observations $d_{M}^{S A R}$ and $\mathrm{N}$ levelling measurements $d_{N}^{\text {level }}$, and the levelling measurements were interpolated to the date of SAR imaging $d_{M}^{\text {level }}$. The average subsidence value of $d_{M}^{S A R}$ and $d_{M}^{\text {level }}$ was regarded as the subsidence value at the date of SAR imaging $d_{M}$ and the time series subsidence information of levelling points $d_{M+N}$ was obtained by combined $d_{M}$ with $d_{N}^{\text {level }}$.

The unknown parameters of exponent Knothe model were estimated based on InSAR with levelling $d_{M+N}$, and only on levelling $d_{N}^{\text {level }}$, respectively. The fitted subsidence values can be obtained by the fitted curve and the dynamic subsidence values in different levelling points can be predicted by the fitted exponent Knothe model. Finally, the fitting and prediction accuracy was analysed by comparing the fitted data and predicted data with the measured data. The impact of InSAR observations on the accuracy of exponent Knothe model was further investigated.

\section{STUDY AREA AND DATA}

One mining workface was selected as the study area, which is located in Huainan, Anhui province. The average mining depth is about $802 \mathrm{~m}$ and the average mining thickness is about $2.7 \mathrm{~m}$. The length of workface along strike direction is about $1150 \mathrm{~m}$ and the length along dip direction is about $260 \mathrm{~m}$. The direction of extraction is from west to east, the extraction time is about during from March 2012 to March 2013 and the average advancing rate is about $4 \mathrm{~m} / \mathrm{d}$. The study area is covered with farmlands, roads, rivers and some infrastructures (Dong et al, 2013, 2015; Zhang et al, 2015a, 2015b).

To minimize the effect of farmlands or vegetation on the interferometric phases, we collected five scenes of C-band ascending Radarsat-2 images acquired in winter with a spatial pixel spacing of $2.66 \mathrm{~m}$ in the range and $2.50 \mathrm{~m}$ in the azimuth. The acquired SAR images spanned from December 2012 to April 2013. The SAR amplitude map of study area located in WGS 84 is shown in Figure 4 and the coverage of workface is denoted by black rectangle. The external DEM used to remove the topography phase of the interferograms was the SRTM DEM with 30 m resolution.

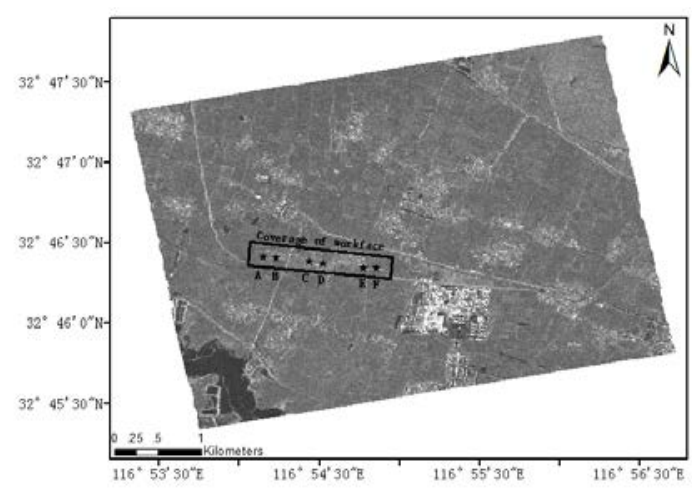

Figure 4. The amplitude map of study area

We collected six levelling measurements from March 2012 to January 2013 and the monitoring result obtained on March 2, 2012 was known as the initial reference data without 
deformation. The date of levelling measurements and SAR imaging was shown in Table 1 . To validate the accuracy of fitting and prediction of exponent Knothe model, six levelling points $\mathrm{A}, \mathrm{B}, \mathrm{C}, \mathrm{D}, \mathrm{E}$ and $\mathrm{F}$ along the strike direction, denoted by black star in Figure 4, were selected to analysis the deformation characteristics. During SAR imaging acquisition, points A and $B$ were in the phase of residual subsidence, points $C$ and $D$ were in the phase of main and residual subsidence, points $\mathrm{E}$ and $\mathrm{F}$ were in the phase of main subsidence.

\begin{tabular}{|c|c|}
\hline Way of monitoring & Date \\
\hline & 20120302 \\
& 20120503 \\
Levelling measurement & 20120604 \\
& 20120905 \\
& 20121027 \\
& 20130112 \\
\hline & 20121205 \\
SAR observation & 20130122 \\
& 20130215 \\
& 20130311 \\
& 20130404 \\
\hline
\end{tabular}

Table 1 . The date of levelling and SAR imaging

\section{RESULTS AND ANALYSIS}

\subsection{Interferometric Results Analysis}

The image acquired on December 5, 2012 was selected as the master image and other four images were co-registered to the common image. Four interferometric pairs were generated by two adjacent co-registered images and their parameters were shown in Table 2.

\begin{tabular}{|c|c|c|c|c|}
\hline ID & Master & Slave & Baseline /m & Time /d \\
\hline 1 & 20121205 & 20130122 & 137.661 & 48 \\
2 & 20130122 & 20130215 & 141.815 & 24 \\
3 & 20130215 & 20130311 & 81.824 & 24 \\
4 & 20130311 & 20130404 & 30.404 & 24 \\
\hline
\end{tabular}

Table 2. Parameters of interferometric pairs

In order to research the main reason of ground deformation, the consistency between the deformation range and the location of workface was analysed. Then four scenes of differential interferograms generated by D-InSAR technique were shown in Figure 5, the coverage of workface is denoted by black rectangle and the centre of subsidence is denoted by black star. It is shown that the deformation range of study area was consistent with the location of workface, so the deformation was mainly induced by coal mining. Furthermore, the centres of interferometric fringe denoted by black star were moved from west to east as the direction of extraction.

The relative ground deformation characteristics along the line of sight (LOS) between two adjacent SAR images obtained by DInSAR technique were shown in Figure 6. The maximum deformation of each time period was about $-0.25 \mathrm{~m},-0.21 \mathrm{~m}$, $0.15 \mathrm{~m}$ and $-0.05 \mathrm{~m}$, respectively. The maximum subsidence was happened during December 2012 and January 2013, the minimum subsidence was happened during March 2013 and April 2013 because of the end of extraction.
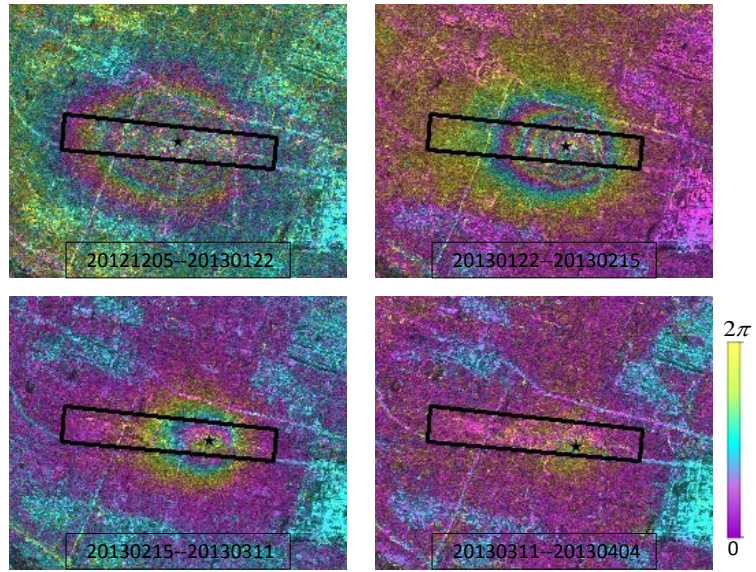

Figure 5. The differential interferograms of study area
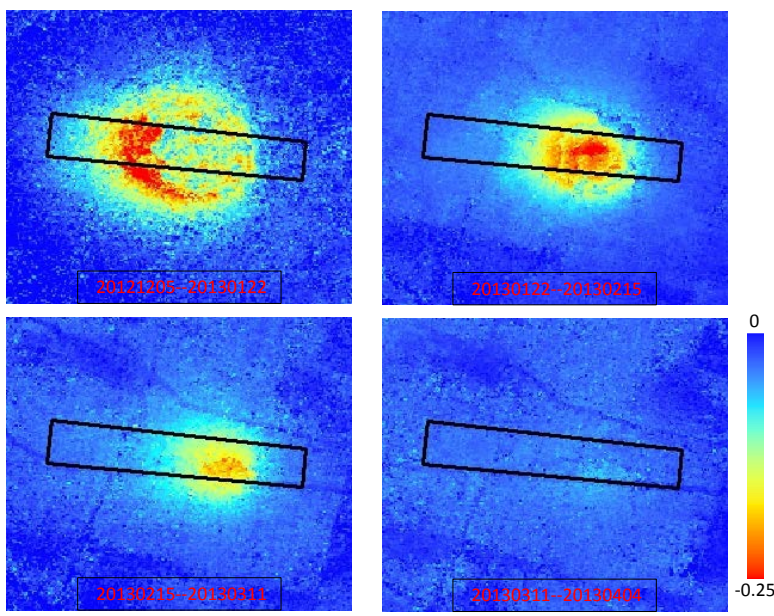

Figure 6. The ground deformation of four interferometric pairs (Unit: $\mathrm{m}$ )

\subsection{Fitting Accuracy Analysis}

To analysis the fitting accuracy of exponent Knothe model, the unknown parameters in six levelling points were estimated by combined levelling with InSAR, and only by levelling, respectively. The unknown parameters values in six points were shown in Table 3.

\begin{tabular}{|c|c|c|c|c|}
\hline Point & Measurement & $w_{m} / \mathrm{m}$ & $c$ & $k$ \\
\hline \multirow{2}{*}{ A } & Levelling and SAR & 0.474 & 0.021 & 7.679 \\
& Levelling & 0.467 & 0.023 & 8.757 \\
\hline \multirow{2}{*}{ B } & Levelling and SAR & 0.598 & 0.022 & 8.969 \\
& Levelling & 0.589 & 0.024 & 10.325 \\
\hline \multirow{2}{*}{ C } & Levelling and SAR & 0.825 & 0.019 & 91.704 \\
& Levelling & 1.042 & 0.013 & 30.768 \\
\hline \multirow{2}{*}{ D } & Levelling and SAR & 0.792 & 0.017 & 90.664 \\
& Levelling & 1.458 & 0.009 & 18.142 \\
\hline \multirow{2}{*}{ E } & Levelling and SAR & 0.432 & 0.019 & 269.32 \\
& Levelling & 234.36 & 0.002 & 2.891 \\
\hline \multirow{2}{*}{ F } & Levelling and SAR & 0.332 & 0.019 & 265.52 \\
& Levelling & 154.37 & 0.002 & 2.763 \\
\hline
\end{tabular}

Table 3. The unknown parameters values in six points

The unknown parameters of exponent Knothe model estimated by combining levelling with InSAR were obviously different 
from the parameters obtained only by levelling, especially in points $\mathrm{E}$ and $\mathrm{F}$. Among them, the parameters obtained only by levelling in points $\mathrm{E}$ and $\mathrm{F}$ were obviously two sets of abnormal values, the difference between parameters obtained by levelling and InSAR with that only by levelling in points $\mathrm{C}$ and $\mathrm{D}$ were much bigger than the difference in points $\mathrm{A}$ and $\mathrm{B}$.

To better compare the fitting and prediction accuracy of exponent Knothe model, the fitted curves and measured data in points A, B, C, D, E and F were shown in Figure 7.
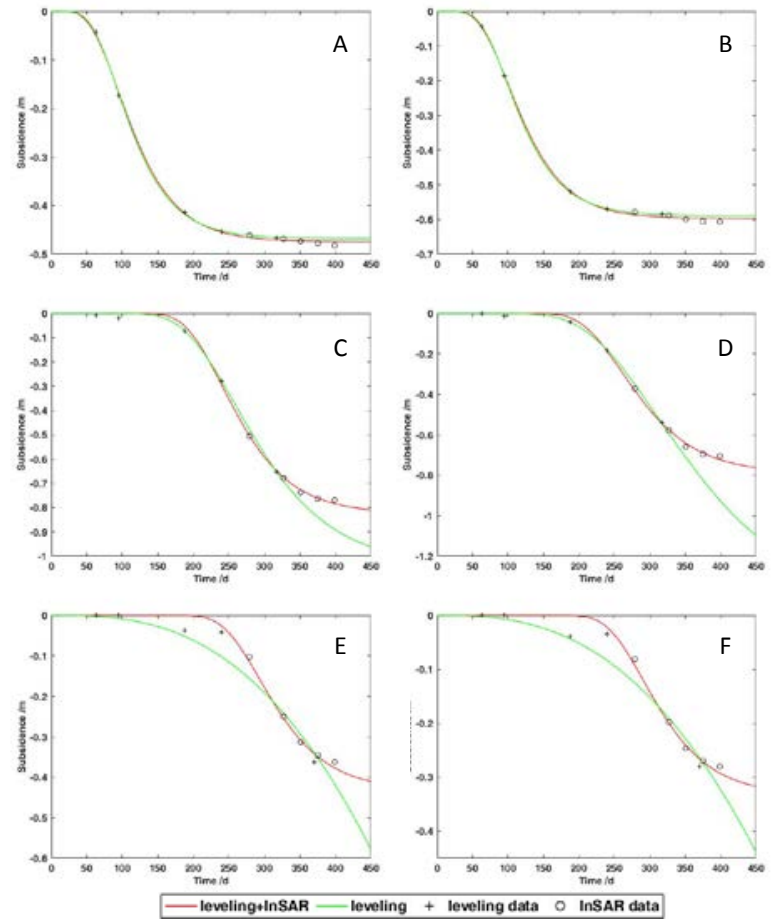

Figure 7. The fitted curves and levelling in six points

As can be seen from Figure 7, the difference between the fitted curve obtained by levelling and InSAR with the curve only by levelling was much less in points A and B than that in other four points. The time of levelling was basically covered with three phase of mining-induced subsidence in points A and B, however, the levelling covered with the phase of initial and main subsidence in points $\mathrm{C}$ and $\mathrm{D}$, the levelling data only covered with initial subsidence in points $\mathrm{E}$ and $\mathrm{F}$. Therefore, the improvement of fitting accuracy was related to the InSAR data and the high precision fitting curve can be obtained by combining levelling measurements and InSAR observations.

In conclusion, the fitting accuracy obtained by levelling and SAR was obviously better than that only by levelling measurements. Therefore, InSAR observations can be important for improving the fitting accuracy of exponent Knothe model.

\subsection{Prediction Accuracy Analysis}

To analysis the prediction accuracy of exponent Knothe model, the subsidence values at five different moments were collected to verify the difference between the predicted data and measured data. The predicted data at five moments achieved by above estimated fitted curve and the levelling measurements at same moments were shown in Figure 8.
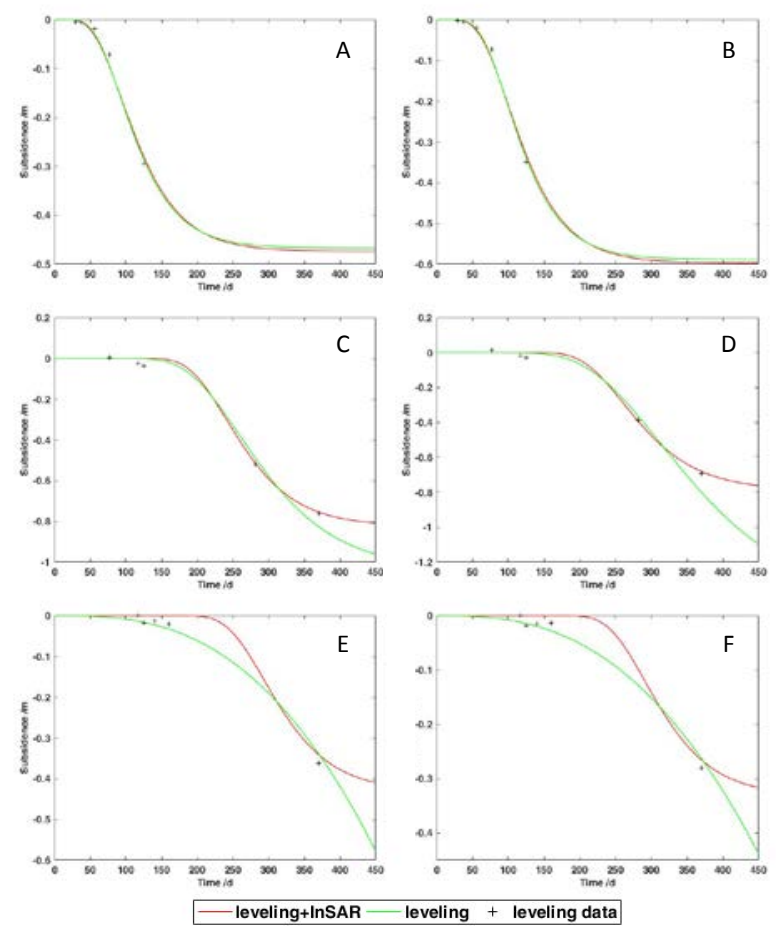

Figure 8. The fitted curve and levelling at five moments

As shown in Figure 8, the error between the predicted data obtained by the red curve with the measured data was obviously less than that by the green curve. And the initial subsidence was not zero in points $\mathrm{E}$ and $\mathrm{F}$ because of the coal mining extraction of advancing positions.

To analysis the prediction accuracy of exponent Knothe model quantitatively, the mean errors were calculated between the predicted data with the measured data in six points, which were shown in Figure 4 . The mean errors obtained by levelling and SAR in points $A, B, C$ and $D$ were less than the values obtained only by levelling. The mean errors obtained by levelling and SAR in points $\mathrm{E}$ and $\mathrm{F}$ were bigger than that only by levelling, but the subsidence curve fitted only by levelling was not fit with the actual mining subsidence process and it was meaningless to compare with the errors.

\begin{tabular}{|c|c|c|}
\hline Point & Measurement & Mean error $/ \mathrm{m}$ \\
\hline \multirow{2}{*}{ A } & Levelling and SAR & 0.0076 \\
& Levelling & 0.0100 \\
\hline \multirow{2}{*}{ B } & Levelling and SAR & 0.0062 \\
& Levelling & 0.0079 \\
\hline \multirow{2}{*}{ C } & Levelling and SAR & 0.0146 \\
& Levelling & 0.0311 \\
\hline \multirow{2}{*}{ D } & Levelling and SAR & 0.0153 \\
& Levelling & 0.0364 \\
\hline \multirow{2}{*}{ E } & Levelling and SAR & 0.0148 \\
& Levelling & 0.0118 \\
\hline \multirow{2}{*}{ F } & Levelling and SAR & 0.0121 \\
& Levelling & 0.0105 \\
\hline
\end{tabular}

Table 4. The mean error values in six points

Above all, the prediction accuracy obtained by levelling and InSAR was obviously better than that only by levelling. So, InSAR measurements were effective for improving the prediction accuracy of exponent Knothe model. 


\section{CONCLUSIONS}

In this paper, we successfully obtained the unknown parameters of exponent Knothe model and predicted subsidence value at different moments in the mining workface by combining InSAR results with levelling measurements.

Compared the fitting and prediction accuracy estimated by InSAR and levelling with only by levelling, it was shown that the accuracy obtained by InSAR and levelling was obviously better than the other one. Therefore, InSAR observations were contribute to improving the fitting and prediction accuracy of exponent Knothe model. However, the number of feature points used to validate the fitting and prediction accuracy of exponent Knothe model in this study was limited and more points were needed to further verify the accuracy later.

In the future, more different mining-induced subsidence models and radar images with higher resolution will be applied to extract more accurate ground subsidence information in coal mining areas.

\section{ACKNOWLEDGEMENTS}

We thank Canadian Space Agency for providing us Radarsat-2 data in this work.

\section{REFERENCES}

Berardino, P., Fornaro, G., Lanari, R., et al, 2002. A new algorithm for surface deformation monitoring based on small baseline differential SAR interferograms. Geoscience and Remote Sensing, IEEE Transactions on, 40(11), pp. 2375-2383.

Chen, Q. F., Niu, W. J., Liu, Y. Z., et al, 2017. Improvement of Knothe model and analysis on dynamic evolution law of strata movement in fill mining. Journal of China University of Mining and Technology, 46(2), pp. 250-256.

Colesanti, C., Mouelic, S. L., Bennani, M., et al, 2005. Detection of mining related ground instabilities using the Permanent Scatterers technique-a case study in the east of France. International Journal of Remote Sensing, 26(1), pp. 201-207.

Cuenca, M. C., Hooper, A. J., Hanssen, R. F., et al, 2013. Surface deformation induced by water influx in the abandoned coal mines in Limburg, The Netherlands observed by satellite radar interferometry. Journal of Applied Geophysics, 88, pp. 111.

Cui, X. M., Wang, J. C., Liu, Y. S., et al, 2001. Prediction of progressive surface subsidence above longwall coal mining using a time function. International Journal of Rock Mechanics and Mining Sciences, 38(7), pp. 1057-1063.

Dong, S. C., Yin, H. W., Yao, S. P., et al, 2013. Detecting surface subsidence in coal mining area based on DInSAR technique. Journal of Earth Science, 24(3), pp. 449-456.

Dong, S. C., Samsonov, S., Yin, H. W., et al, 2015. Spatiotemporal analysis of ground subsidence due to underground coal mining in Huainan coalfield, China. Environmental Earth Sciences, 73(9), pp. 5523-5534.
Du, Z. X., Yang, F. L., Liu, G. L., et al, 2007. The discussions on GPS and InSAR data integrating and applying in monitoring subsidence and deformation of mines exploitation. Science of Surveying and Mapping, 32(1), pp. 55-57.

Gao, Y. F., Jia, J.Y., Li, B., et al, 2009. The attenuation function of surface subsidence and stability analysis due to mining. Journal of China Coal Society, 34(7), pp. 892-896.

Guo, G. L., Zhu, X. J., Zha, J. F., et al, 2014. Subsidence prediction method based on equivalent mining height theory for solid backfilling mining. Transactions of Nonferrous Metals Society of China, 24(10), pp. 3302-3308.

Han, H. L., Hu, N. L., Cui, B., 2012. Dynamic Modeling of Surface Subsidence Induced by Underground Mining. Advanced Materials Research, Trans Tech Publ, 382, pp. 323327.

Hu, Q. F., Cui, X. M., Wang, G., et al, 2011. Key Technology of Predicting Dynamic Surface Subsidence Based on Knothe Time Function. Journal of Software, 6(7), pp. 1273-1280.

Lian, X. G., Jarosz, A., Saavedra-rosas, J., et al, 2011. Extending dynamic models of mining subsidence. Transactions of Nonferrous Metals Society of China, 21(S3), pp. 536-542.

Liu, Y. C., Cao, S. G., Liu, Y. B., 2010. Discussion on some time functions for describing dynamic course of surface subsidence due to mining. Rock and Soil Mechanics, 31(3), pp. 925-930.

Shen, Z., Xu, L. J., Guo, H., et al, 2016. An improved dynamic deformation model of mining subsidence. Science of Surveying \& Mapping, 41(12), pp. 238-242.

Wang, Z. J., Li, G. J., You, B., et al, 2012. Application of probability integral method in ground deformation prediction. Global Geology, 15(3), pp. 237-240.

Xi, G. J., Hong, X., Shao, H. Q., 2013. Application of Improved Logistic Function Model to Prediction of Surface Subsidence. Coal Science and Technology, 41(8), pp. 114-117.

Yang, Z. F., Zhu, J. J., Li, Z. W., et al, 2015. Analysis of law of kinematic mining subsidence by integrating InSAR and leveling measurements. Journal of Central South University (Science and Technology), 46(10), pp. 3743-3751.

Yang, Z. F., Yi, H. W., Zhu, J. J., et al, 2016. Spatio-temporal evolution law analysis of whole mining subsidence basin based on InSAR-derived time-series deformation. The Chinese Journal of Nonferrous Metals, 26(7), pp. 1515-1522.

Yerro, A., Corominas, J., Monells, D., et al, 2014. Analysis of the evolution of ground movements in a low densely urban area by means of DInSAR technique. Engineering Geology, 170, pp. 52-65.

Zebker, H. A., Goldstein, R. M., 1986. Topographic mapping from interferometric synthetic aperture radar observations. Journal of Geophysical Research, 91(B5), pp. 4993-4999.

Zhang, B., Cui, X. M., Hu, Q. F., 2016. Study on normal distributed time function model to dynamically predict mining subsidence. Coal Science and Technology, 44(4), pp. 140-146. 
Zhang, B., Cui, X. M., 2017. Optimization of segmented Knothe time function model for dynamic prediction of mining subsidence. Rock and Soil Mechanics, 38(2), pp. 541-549.

Zhang, W. Z., Zou, Y. F., Ren, X. F., 2009. Research on Logistic Model in Forecasting Subsidence Single-Point During Mining. Journal of Mining and Safety Engineering, 26(4), pp. 486-489.

Zhang, X. R., Liu, Y. C., 2012. Knothe Time Functions and Their Application in Dynamic Subsidence on the Ground. Surveying and Mapping of Geology and Mineral Resources, 28(3), pp. 14-16.

Zhang, Z. J., Wang, C., Tang, Y. X., et al, 2015a. Analysis of ground subsidence at a coal-mining area in Huainan using timeseries InSAR. International Journal of Remote Sensing, 36(23), pp. 5790-5810.

Zhang, Z. J., Wang, C., Tang, Y. X., et al, 2015b. Subsidence monitoring in coal area using time-series InSAR combining persistent scatterers and distributed scatterers. International Journal of Applied Earth Observation and Geoinformation, 39, pp. 49-55. 